\title{
Extreme Climate-Induced Life-History Plasticity in an Amphibian
}

\author{
François S. Becker, ${ }^{1,2}$ Krystal A. Tolley, ${ }^{1,3}$ G. John Measey, ${ }^{4}$ and Res Altwegg ${ }^{2,5, *}$
}

1. South African National Biodiversity Institute, Cape Town, South Africa; 2. Centre for Statistics in Ecology, Environment and Conservation, Department of Statistical Sciences, University of Cape Town, Cape Town, South Africa; 3. Centre for Ecological Genomics and Wildlife Conservation, Department of Zoology, University of Johannesburg, Auckland Park 2000, Johannesburg, South Africa; 4. Centre of Excellence for Invasion Biology, Stellenbosch University, Stellenbosch, South Africa; 5. African Climate and Development Initiative, University of Cape Town, South Africa

Submitted September 26, 2016; Accepted July 21, 2017; Electronically published December 19, 2017

Online enhancements: appendix, video files. Dryad data: http://dx.doi.org/10.5061/dryad.rr6rt.

\begin{abstract}
A BSTRACt: Age-specific survival and reproduction are closely linked to fitness and therefore subject to strong selection that typically limits their variability within species. Furthermore, adult survival rate in vertebrate populations is typically less variable over time than other life-history traits, such as fecundity or recruitment. Hence, adult survival is often conserved within a population over time, compared to the variation in survival found across taxa. In stark contrast to this general pattern, we report evidence of extreme short-term variation of adult survival in Rose's mountain toadlet (Capensibufo rosei), which is apparently climate induced. Over 7 years, annual survival rate varied between 0.04 and 0.92 , and $94 \%$ of this variation was explained by variation in breeding-season rainfall. Preliminary results suggest that this variation reflects adaptive life-history plasticity to a degree thus far unrecorded for any vertebrate, rather than direct rainfall-induced mortality. In wet years, these toads appeared to achieve increased reproduction at the expense of their own survival, whereas in dry years, their survival increased at the expense of reproduction. Such environmentally induced plasticity may reflect a diversity of life-history strategies not previously appreciated among vertebrates.
\end{abstract}

Keywords: adaptive plasticity, capital breeder, ectotherm, rainfall, survival, toad.

\section{Introduction}

Life-history traits, such as survival and recruitment, can be highly variable among species but tend to be well conserved within species (Stearns 1980, 1983). As a result of fundamental trade-offs between adult survival and reproduction, species tend to fall along a continuum ranging from species

\footnotetext{
* Corresponding author; e-mail: res.altwegg@gmail.com. ORCIDs: Altwegg, http://orcid.org/0000-0002-4083-6561; Becker, http://orcid .org/0000-0003-3874-9183; Measey, http://orcid.org/0000-0001-9939-7615.

Am. Nat. 2017. Vol. 191, pp. 250-258. (C) 2017 by The University of Chicago. 0003-0147/2018/19102-57291\$15.00. All rights reserved. DOI: $10.1086 / 695315$
}

with large brood sizes and low adult survival to species with small brood sizes but high adult survival (Stearns 1992; Sæther et al. 1996). These life-history syndromes are buffered against environmental variation, and the life-history traits that are most closely related to fitness, such as survival and fertility, tend to be the least variable (Pfister 1998; Ehrlén 2003; Gaillard and Yoccoz 2003). Under what conditions should we expect to find exceptions to such canalized lifehistory strategies, such as strategies that are strongly determined by the environment?

An organism's life-history strategy affects how much reproduction and the chance of surviving vary from year to year. Some organisms adjust their reproductive investment on the basis of current energy acquisition ("income breeders"), while others rely on stored reserves ("capital breeders"; Drent and Daan 1980). Capital breeding is associated with the tendency toward semelparity, that is, spending all energy in one reproductive event and then dying (Bonnet et al. 2002). Among vertebrates, capital breeding and semelparity are relatively more common in ectotherms than in endotherms (Bonnet et al. 1998).

Variable environments generally select for iteroparous life-history strategies; that is, organisms spread their reproductive investments across multiple occasions during their lifetime (Benton and Grant 1999). Iteroparous organisms essentially hedge their bets to reduce the risk of losing their entire reproductive investment if the environmental conditions turn out unfavorable in a particular year. However, if fecundity is more sensitive to environmental variation than survival, then the optimal reproductive effort tends to increase toward semelparity (Ranta et al. 2002).

One of the most important sources of environmental variation is climatic variation, which has become more variable and prone to extreme events as a result of anthropogenic influences on global climate (Ummenhofer and Meehl 2017). 
An important question, therefore, is how changes in climatic variation affect organisms. Recent reviews suggest that organisms cope with a changing climate mainly through phenotypic plasticity (Merilä and Hendry 2014; Urban et al. 2014).

Environmental fluctuations tend to select for phenotypic plasticity of life-history traits most strongly if they are short, compared to generation time, as well as being predictable (Bårdsen et al. 2011; Botero et al. 2015). Experimental evidence confirms that long-lived organisms show plasticity in reproductive investment: when conditions are favorable, reproductive investment is increased, but when conditions are unfavorable, it is decreased in favor of individual survival and somatic growth (e.g., Gaillard et al. 1998; Bårdsen et al. 2008). Within clades of long-lived vertebrates, the plasticity in reproductive investment is restricted, so that adult survival remains relatively stable over time (Stearns 1992; Gaillard et al. 1998; Pfister 1998; Jones et al. 2014).

In shorter-lived species, where the chances to reproduce are fewer, there are conditions under which we would expect strong plasticity to evolve not only in reproduction but also in age-specific survival. These conditions include (1) a clear trade-off between current reproduction and future survival, (2) short environmental fluctuation with highly reliable cues, and (3) environmental conditions that favor one particular fitness component. Under these three conditions, we expect that organisms evolve life-history strategies that invest in reproduction at the expense of survival when the environmental conditions are favorable for reproduction and have relatively high survival when conditions are unfavorable for reproduction.

Among vertebrates, these conditions are most likely to be met among ectothermic capital breeders, because they can store reproductive potential until conditions are favorable for reproduction. We further expect these conditions to be found in organisms with complex life cycles where offspring occupy habitats different from those of adults, because the different life stages are likely to be affected by environmental variation in different ways. For example, amphibians breeding in temporary ponds have tadpoles whose survival is strongly affected by the hydroperiod, whereas adults can survive dry periods more easily. The hydroperiod, in turn, is determined by rainfall during the breeding season and therefore is fairly predictable in areas with clear rainfall seasonality. We therefore hypothesize that rainfall can induce strong life-history plasticity in such species. Currently, detailed demographic studies of such species are rare, compared to our detailed understanding of the demography of endothermic vertebrates such as birds (Sæther 1988) and mammals (Stearns 1983). The degree of plasticity in vertebrate life histories might therefore be underestimated.

We conducted a capture-mark-recapture (CMR) study to estimate annual adult survival and recruitment in a population of Rose's mountain toadlet (Capensibufo rosei) be- tween 2008 and 2014. In contrast to the consistent pattern of survival typical for a vertebrate, we report evidence for large, environmentally induced plasticity in survival and recruitment within this amphibian population. We suggest that this may reflect adaptive plasticity according to expected patterns for short-lived species living in fluctuating environments.

\section{Methods \\ Study Site and Study Species}

Capensibufo rosei (Rose's mountain toadlet) is a small $(<3-\mathrm{cm}$ body length) bufonid (fig. A1; figs. A1-A5 are available online) that is endemic to the Cape Peninsula, in the Western Cape Province of South Africa (Cressey et al. 2015; Channing et al. 2017). To our knowledge, this species occurs in only two isolated populations, one of which is our study population in the Silvermine section of Table Mountain National Park $\left(34.10^{\circ} \mathrm{S}, 18.44^{\circ} \mathrm{E}\right)$. This population persists in a small $(<5-\mathrm{ha})$ basin surrounded by mountains. The area is characterized by Peninsula sandstone fynbos vegetation, with wetlanddependent plants in the basin area, including, for example, Leucadendron, Erica, Brunia, Drosera, and Restionaceae (Rebelo et al. 2006).

The breeding period starts in late July or August and lasts 2-4 weeks. The male toadlets form dense breeding aggregations (up to 200) in small, ephemeral pools that form during seasonal rainfall (fig. A2). Yearly thorough searches revealed that, despite the large number of available pools, only a few pools are used for breeding (1-10 breeding pools per year during the course of the study), while the surrounding pools are unused. The pools are typically less than $3 \mathrm{~cm}$ deep and are $10-80 \mathrm{~cm}$ in diameter (figs. A2, A3; videos A1 and A2, available online; also see Edwards et al. 2017). Unlike most frogs, the males do not have an advertisement call (Grandison 1980) but actively move within and between breeding pools in search of females. Females arrive at the pools individually over the course of several weeks. Multiple males may form a "breeding ball" (video A1), which occasionally results in fatalities in both sexes. Females depart immediately after ovipositing (strings of approximately 100 eggs 2 $3 \mathrm{~mm}$ in diameter). Age at first breeding is not known. Given the small size of the toads, we assume that they can start breeding after 1 year. However, we have observed very small individuals just before the breeding season (ca. $1.0-1.5 \mathrm{~cm}$ ); hence, at least some individuals might take 2 years to reach reproductive body size. Before this study, no survival estimates existed for this species.

Tadpoles develop over 2 months, with metamorphosis (metamorphs have a ca. 5-mm body length) taking approximately 1 month (Edwards et al. 2017). The diet of the tadpoles is not known, although the presence of a large yolk sac 
throughout most of their development suggests that they have a large energy reserve. Predation on tadpoles has not been observed, and other than tadpoles the shallow pools generally contain only amphipods and flatworms, which presumably feed on detritus and have not been observed feeding on live eggs or on tadpoles. Insect larvae are usually not observed in the breeding pools, and we have not observed any other macroinvertebrates. Typically, metamorphosis occurs as the pools begin to dry out. However, in low-rainfall years, pools occasionally dry before metamorphosis is complete, causing tadpole mortality in some pools (fig. A4; Edwards et al. 2017).

\section{Capture-Mark-Recapture Study Design}

We used capture-mark-recapture (CMR) methods to estimate apparent survival and recruitment rates of adult C. rosei. This species is an explosive breeder, and capture and marking were performed during breeding events. We thoroughly searched the entire range of this population for breeding pools and then sampled all major pools (over the seven years 2008-2014, between one and three pools). Capture sessions took place every 3-8 days, allowing time for the breeding to continue unperturbed between capture sessions. Toadlets were captured by hand and placed in a plastic container for marking, after which they were released into the same pool. Because of the high concentration of (primarily male) toadlets in the small breeding puddles, capture events were very efficient, yielding large numbers of animals in a short time. Each toadlet was given a year-specific batch mark (the distal phalange of one particular toe for that year was clipped) on first capture and again if recaptured in subsequent years. Hence, each toadlet carries its annual capture history in the form of a combination of annual batch marks. Because of the low probability of recapture and possibly because of a short life span, the toads were typically marked only once or twice; no individuals received more than three marks during the course of this study. Our analyses included 1,377 captured toadlets and spanned seven years, between 2008 and 2014. Because identification of sex was not always certain, we made no attempt to estimate demographic parameters for the sexes separately.

\section{Data Analysis and Model Descriptions}

We used Cormack-Jolly-Seber (CJS)-type models (Lebreton et al. 1992) in program MARK (White and Burnham $1999)$ to estimate apparent survival probabilities $(\phi)$ and Pradel survival and recruitment models (Pradel 1996) to estimate per capita rate of recruitment into the breeding population $(F)$. The demographic models used do not discriminate between local mortality and permanent emigration or between local recruitment and immigration. However, we assumed that no significant movement into or out of the sampled population occurred: the sampled population is genetically isolated from the nearest other breeding site, $\sim 20 \mathrm{~km}$ away (Cressey et al. 2015). It has a very small range ( $<5 \mathrm{ha})$, and all major breeding pools within the population range were sampled each year. Hence, the apparent survival probability $(\phi)$ and apparent recruitment rate $(F)$ are likely accurate estimates for true survival and recruitment, respectively.

The live-encounter CJS models estimate two types of parameters: (1) the apparent survival rate $\left(\phi_{i}\right)$, which is the per capita probability of surviving from the breeding season in year $i$ to the breeding season in year $i+1$, and (2) the recapture rate $\left(p_{i}\right)$, which is the probability of an individual to be captured in year $i$, given that it is alive in year $i$. Our starting model was the fully time-dependent model, $\phi_{\text {year }} p_{\text {year, }}$ where each of the parameters was allowed to vary fully among years. This model was used for goodness-of-fit testing in program U-CARE (Choquet et al. 2009). There was no evidence of lack of fit $\left(\chi^{2}=9.151, \mathrm{df}=11, P=.61\right)$.

Pradel survival and recruitment models read the capture histories backward in time to exploit the information in the data on when an individual entered the breeding population, that is, recruitment. The version of this model that we used estimates three types of parameters: survival rate $(\phi)$, recapture rate $(p)$, and per capita recruitment rate $(F)$. The first two parameters are defined as in the CJS model, and $F_{i}$ is the number of new arrivals/recruits in the population in year $i$ per animal originally present in the population in year $i$. For fully time-dependent survival and recruitment models, the first recruitment rate is confounded with the first recapture rate and the last survival rate estimate is confounded with the last recapture rate.

\section{Model Covariates and Interpretation}

Aquatic-breeding amphibians are typically dependent on rainfall for breeding and survival and can desiccate because of their sensitive, porous skin (Withers et al. 1984; Hillman et al. 2014). Therefore, in our CJS models, we examined the effect of rainfall on survival rates, using two different covariates. The covariate "total annual rainfall" (fig. 1a) is the total rainfall in millimeters from October in year $i$ (i.e., strictly after the $i$ th capture occasion) until June in year $i+1$ (i.e., strictly before capture occasion $i+1$ ). The covariate "breeding-season rainfall" (fig. $1 b$ ) is the mean monthly rainfall for July and August (i.e., when breeding commences), in millimeters per month, from year $i$. Rainfall data were obtained from a weather station $\sim 600 \mathrm{~m}$ west of the breeding site as monthly totals. The level of fluctuations in rainfall during the breeding season reported during this study 

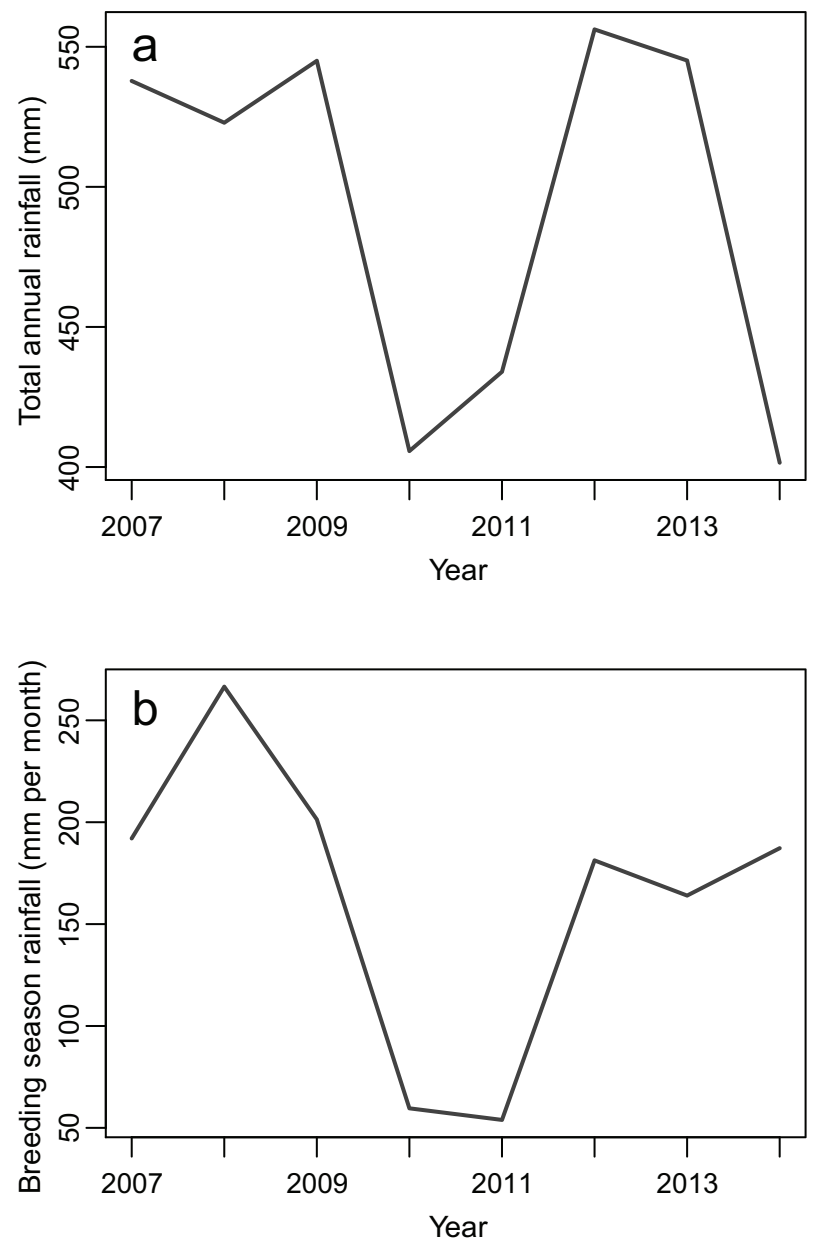

Figure 1: $a$, Total annual rainfall (in $\mathrm{mm}$ ) between capture occasions - from October in year $i$ to June in year $i+1$, from 2007 until 2014. $b$, Breeding-season rainfall (mm per month), the mean monthly rainfall of the months July and August in year $i$, when breeding commences.

appears to be usual for this area (see fig. A5). For the liveencounter CJS models, we considered models that constrained the recapture rate to be a function of capture effort, measured as the number of sampling days in a particular year and number of people per sampling day. We assumed a logit link function for these covariates. Since the covariates were directly incorporated into the CMR models, inference about them fully accounts for the uncertainty in the data.

Pradel survival and recruitment models were further used to investigate the effect of rainfall (total annual rainfall and breeding-season rainfall) on per capita recruitment. Because the toads apparently recruit at either 1 or 2 years of age, we considered three covariate models for each of the two rainfall covariates: (1) rainfall from year $i-1$, which assumes 1 year to reach sexual maturity (and thus enter the breeding population, i.e., recruitment), (2) rainfall from year $i-2$, which assumes 2 years to reach sexual maturity, and (3) the mean rainfall from years $i-2$ and $i-1$. These covariates were included in the models assuming a log link function. In addition to the covariate models, a model with a fully time-dependent recruitment model and one with constant recruitment were also included. The recruitment covariates were included in the models assuming a log link function. In all Pradel models tested, both survival rate $(\phi)$ and recapture rate $(p)$ were allowed to vary fully with time.
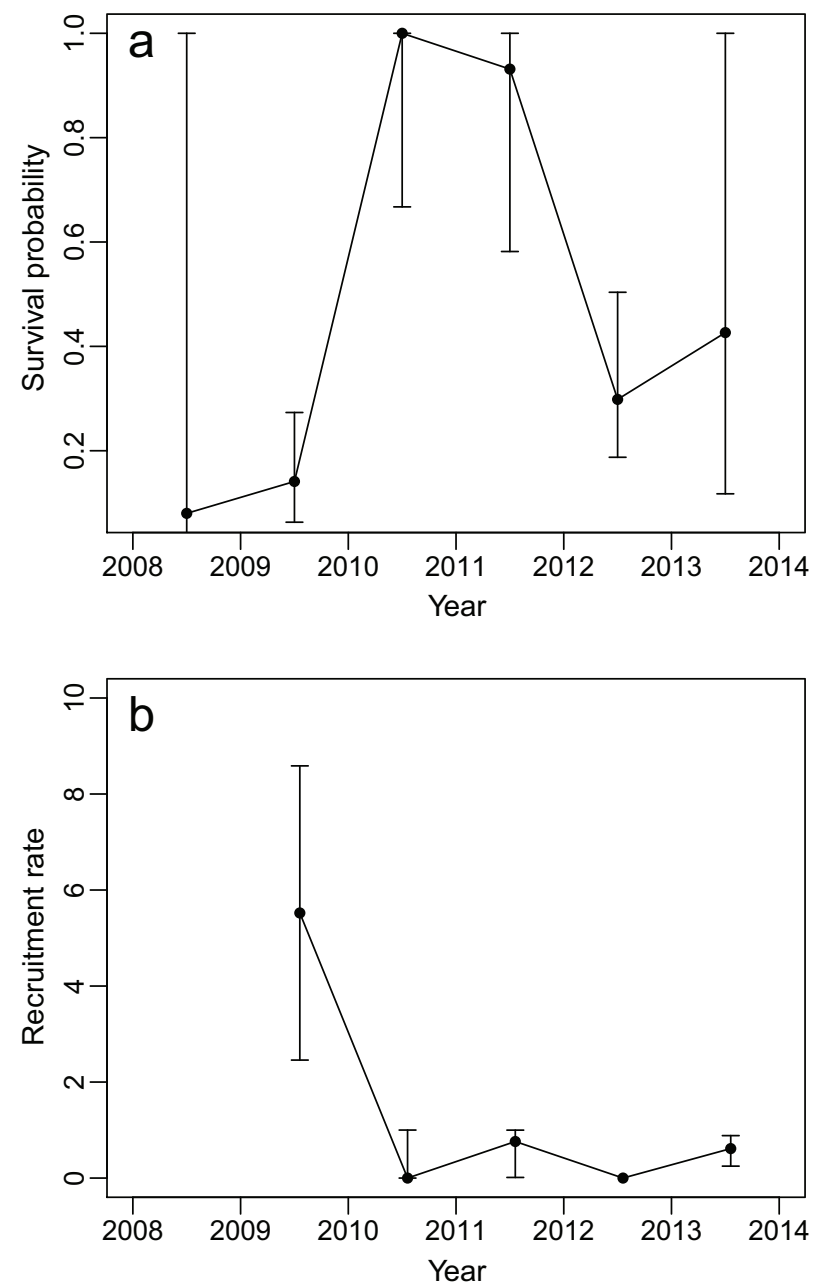

Figure 2: $a$, Annual (per capita) survival rate over the study period, based on model S2 (table 1), where survival and recapture probabilities were both fully time dependent and included $n=1,377$ individuals. Error bars indicate $95 \%$ confidence intervals. $b$, Annual (per capita) recruitment rate, $F$, from model R3 (table 2, based on $n=$ 1,377 individuals), in which recruitment rate and survival and recapture probabilities were all time dependent. Recruitment rate is the number of newly recruited adults in the population per adult present and can thus exceed 1 . The bars indicate $95 \%$ confidence intervals. The first recruitment parameter was not estimable in this model and was excluded from the graph. 


\section{Model Selection and Analysis of Deviance}

We used Akaike's information criterion (corrected for small sample size: AICc; Burnham and Anderson 2002) to rank the models and determine the most important model constraints on survival rate $(\phi)$, recruitment rate $(F)$, and recapture rate $(p)$. We used analysis of deviance (ANODEV; Skalski et al. 1993 ) to calculate the amount of variation in survival or recruitment rate explained by covariates, for the AIC-best models:

$V$ (proportion of total variance explained over time)

$$
=\frac{\text { deviance }_{\text {constant model }}-\text { deviance }_{\text {covariate model }}}{\text { deviance }_{\text {constant model }}-\text { deviance }_{\text {time-dependent model }}} \text {. }
$$

\section{Results}

Both survival rate and recruitment rate fluctuated considerably over time (fig. 2). The live-encounter capture-markrecapture model with survival rate constrained by breedingseason rainfall (model S1; table 1) was clearly the most parsimonious model, with $\sim 9$ times more support from the data than the next-AIC-best model (table 1; ratios of Akaike weights). The estimated apparent survival rate was negatively related to breeding-season rainfall (fig. $3 a$ ), which explained $94 \%$ of the total variability in apparent survival rate (table 1; ANODEV comparing models S1, S2, and S6: $F_{1,3}=$ $49.39, P=.006$ ). The annual apparent survival rate (from model S1) ranged from 0.92 in the year with $54 \mathrm{~mm}$ of breeding-season rainfall to 0.04 in the year with $267 \mathrm{~mm}$. None of the models in which the recapture rate was constrained by capture effort was well supported by the data (table 1; models S4 and S5).

There was a significant positive relationship $(t=5.07$, $\mathrm{df}=3, P=.015)$ between breeding-season rainfall and the observed period of active breeding (fig. $3 b$ ) and a positive relationship between the standardized adult abundance at the breeding site and breeding-season rainfall (fig. $3 c$ ), although this relationship was not significant $(t=2.11$, df $=$ 3, $P=.13)$.

The Pradel models suggested a positive relationship between mean breeding-season rainfall of years $i-1$ and $i-2$, and per capita recruitment rate in year $i$ (fig. $3 d$ ), even though this relationship was driven by the one year with more than $200 \mathrm{~mm}$ of rain. The model with recruitment rate constrained by breeding-season rainfall was the most parsimonious model (model R1; table 2), and breeding season rainfall explained $68 \%$ of the variability in recruitment rate (ANODEV comparing models R1, R3, and R6: $F_{1,3}=6.33$, $P=.086)$.

The estimated recapture probabilities ranged from 0.07 (95\% confidence interval [CI]: 0.04-0.11) to 1.00 (95\% CI: $0.99-1.00)$ in the best survival model (model S1; table 1) and from 0.03 (95\% CI: $0.02-0.04)$ to 1.00 (95\% CI: 0.991.00 ) in the best recruitment model (model R1; table 2).

\section{Discussion}

We found that adult survival in Capensibufo rosei was highly variable from year to year (see fig. $2 a$ ) and that $94 \%$ of this variability was explained by variation in breeding-season rainfall (see fig. $3 a$ ). Wet years were associated with low survival and dry years with high survival. We argue that the observed survival patterns could be a result of $C$. rosei having evolved to invest more heavily in reproduction during highrainfall years than during low-rainfall years.

Three lines of evidence suggest that $C$. rose $i$ has evolved a life-history strategy that adaptively responds to climatic variation rather than that survival is directly affected by rainfall. First, we found a significant positive relationship

Table 1: Live encounter capture-mark-recapture model selection for estimating apparent survival $(\phi)$ and recapture rate $(p)$, for Rose's mountain toadlet, Cape Peninsula, South Africa

\begin{tabular}{|c|c|c|c|c|c|c|c|}
\hline Model & $\phi$ covariate & $p$ covariate & $\mathrm{AICc}$ & $\Delta \mathrm{AICc}$ & $w$ & K & Deviance \\
\hline S1 & Breeding-season rainfall & Year & 853.82 & .00 & .83 & 8 & 837.66 \\
\hline S2 & Year & Year & 858.13 & 4.31 & .10 & 11 & 835.84 \\
\hline S3 & Total annual rainfall & Year & 858.65 & 4.83 & .07 & 8 & 842.49 \\
\hline S4 & Year & Sampling days & 866.38 & 12.56 & .00 & 8 & 850.23 \\
\hline S5 & Year & People per sampling day & 867.89 & 14.07 & .00 & 8 & 851.74 \\
\hline S6 & Constant & Year & 881.78 & 27.96 & .00 & 7 & 867.65 \\
\hline
\end{tabular}

Note: AICc denotes Akaike's information criterion (corrected for small sample sizes), where lower values indicate better model fit; $\Delta$ AICc denotes the difference in AICc between the current model and the best model; Akaike weights $(w)$ measure the relative support that the current model has from the data, compared to the other models; $K$ is the number of parameters estimated in the current model; Deviance is the difference in $-2 \log$ likelihood between the current model and the saturated model, or a model with the number of parameters equal to the sample size. Each model is given a number, and the model covariates used to constrain either apparent survival rate ( $\phi$ covariate) or recapture rate ( $p$ covariate) are displayed for the current model; the covariate "year" denotes full-time dependence. The analysis of deviance used to estimate the proportion of temporal variance in survival explained by breeding-season rainfall was based on models 1,2 , and 6 . 

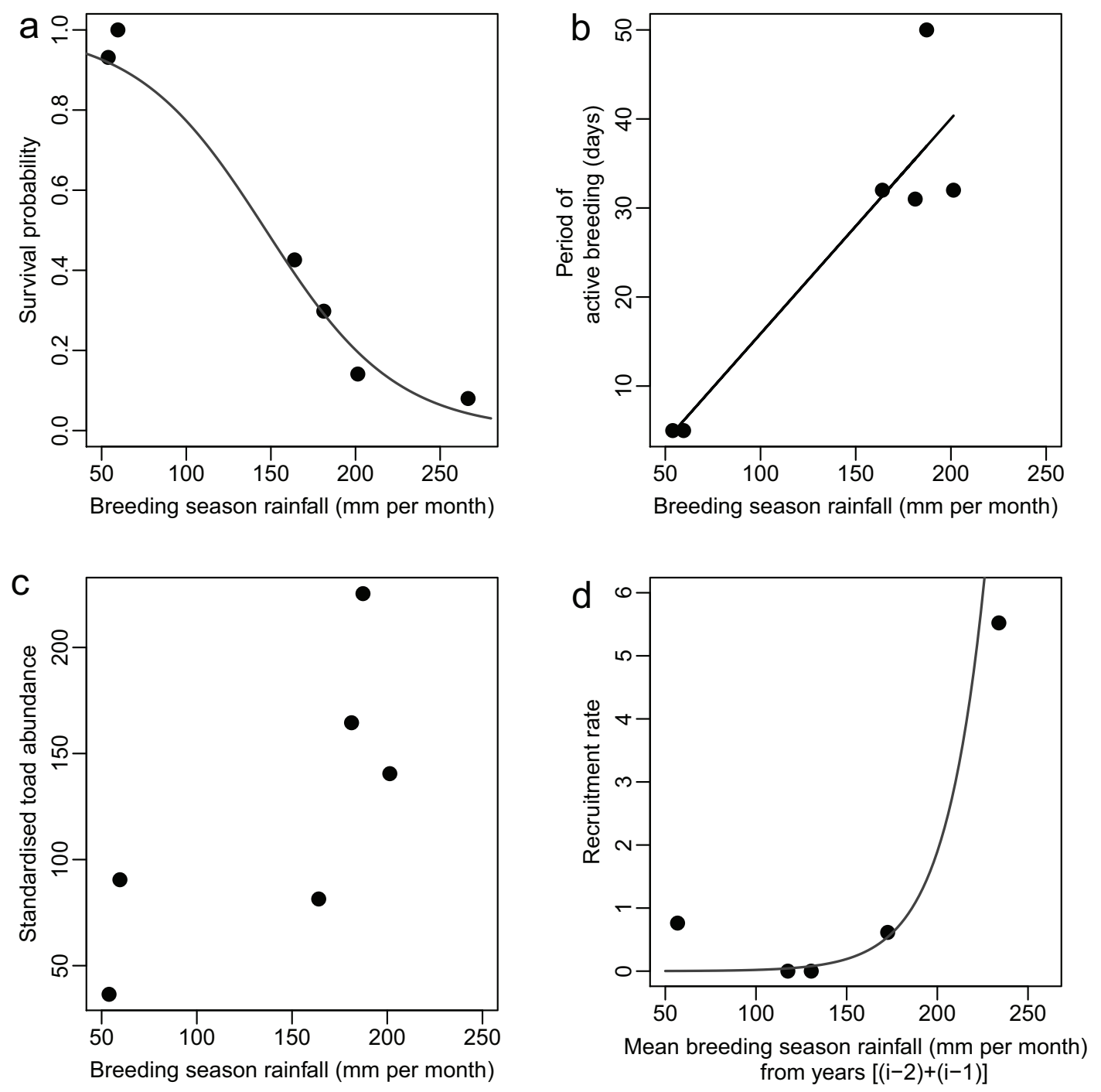

Figure 3: $a$, Annual survival rate in relation to breeding-season rainfall (from years 2008-2013). Dots are for estimated survival rates per year from model S2 (table 1); the line shows the best-fitting logit-linear relationship from model S1 (table 1). Analysis of deviance shows that $94 \%$ of the variability in survival rate over time is explained by breeding-season rainfall in year $i . b$, Breeding period (number of days between first and last observed adult activity at the breeding puddles) in relation to breeding-season rainfall (from years 2009-2014-all dates for which data on breeding period were available). The line shows the best-fitting linear regression model $(t=5.07, \mathrm{df}=3, P=.015)$. $c$, Standardized abundance at breeding site (number of toads sampled per person per sampling day) in relation to breeding-season rainfall (from years 2009-2014 - all dates for which data on standardized abundance were available). The linear regression is nonsignificant $(t=2.11$, df $=3$, $P=.13) . d$, Annual recruitment rate (per capita), in relation to breeding-season rainfall (2-year mean rainfall from mean $(2008+2009)$ to mean $(2012+2013)$ ). Dots are for estimated recruitment rates per year from model R3 (table 2); the line shows the best-fitting logit-linear relationship from model R1 (table 2). Analysis of deviance shows that $68 \%$ of the variability in recruitment rate over time is explained by mean breeding-season rainfall of years $[(i-2)+(i-1)]$.

between breeding-season rainfall and the observed period of active breeding (see fig. $3 b$ ), despite the persistence of water in the breeding pools for several weeks after conclusion of breeding. Male C. rosei are voiceless (Grandison 1980) and rely on ambushing females as they come to the pools for breeding. The length of time a male toadlet stays at the breed- ing site should therefore be directly proportional to his opportunities for mating. As in other amphibians (Morton 1981; Lemckert and Shine 1993), male C. rosei cannot forage while waiting in the water for females to arrive and therefore lose considerable weight during the breeding season. This could explain low survival after extended breeding seasons 
Table 2: Pradel model selection for estimating survival rate $(\phi)$, recapture rate $(p)$, and recruitment rate $(F)$, for Rose's mountain toadlet at Silvermine, South Africa

\begin{tabular}{lllrrrrr}
\hline Model & \multicolumn{1}{c}{$F$ covariate } & \multicolumn{1}{c}{ Lag } & AICc & $\Delta$ AICc & $w$ & $K$ & Deviance \\
\hline R1 & Breeding-season rainfall & Mean $[(i-2)+(i-1)]$ & $5,376.49$ & .00 & .36 & 13 & $5,350.24$ \\
R2 & Total annual rainfall & Mean $[(i-2)+(i-1)]$ & $5,377.41$ & .92 & .23 & 13 & $5,351.16$ \\
R3 & Year & & $5,378.04$ & 1.55 & .17 & 16 & $5,345.67$ \\
R4 & Total annual rainfall & $i-2$ & $5,378.54$ & 2.05 & .13 & 13 & $5,352.29$ \\
R5 & Breeding-season rainfall & $i-2$ & $5,379.14$ & 2.65 & .10 & 13 & $5,352.89$ \\
R6 & Constant & & $5,384.11$ & 7.62 & .01 & 12 & $5,359.90$ \\
R7 & Breeding-season rainfall & $i-1$ & $5,386.10$ & 9.61 & .00 & 13 & $5,359.85$ \\
R8 & Total annual rainfall & $i-1$ & $5,386.14$ & 9.65 & .00 & 13 & $5,359.90$ \\
\hline
\end{tabular}

Note: In all models, $\phi$ and $p$ were allowed to vary fully with time, while $F$ was constrained using different covariates- that is, $\phi_{\text {year }}, p_{\text {year }}$ and $F(x)$. The $F$ covariate denotes covariates used to constrain recruitment rate. The covariate "year" denotes full-time dependence; the covariates "total annual rainfall" and "breeding-season rainfall" were entered with three different time lags: previous year $(i-1)$, two years earlier $(i-2)$, or the average between the two years $(\operatorname{mean}[(i-2)+(i-1)])$. The analysis of deviance used to estimate the proportion of temporal variance in recruitment explained by breeding-season rainfall was based on models R1, R3, and R6. See the table 1 note for more detail.

caused by higher rainfall. Second, although this relationship was not significant, the number of toads participating in breeding appears to be higher during years of high rainfall (see fig. 3c). Increased male number (hence density) may increase competition between males, thus having negative consequences for male survival. Because females arrive individually at the breeding pool, many males compete to fertilize eggs, resulting in occasional fatalities. In addition, males may expend more energy competing for access to females in years of higher density, with likely negative effects on their survival after the breeding season. Third, we expected the recruitment rate to relate positively to the breeding-season rainfall (of the previous year or two, depending on the time to sexual maturity). Our results tentatively supported this expectation, as we found a particularly high recruitment rate after the wettest 2-year period (see table 2, model R1; fig. $3 d$ ).

We found extreme variation in $C$. rosei adult survival that was tightly linked to rainfall and argue that this represents life-history plasticity to a degree not yet described in a vertebrate. Phenotypic plasticity in response to changing climatic variables has been shown in several other studies (see Merilä and Hendry 2014; Urban et al. 2014). However, these examples of plasticity were generally limited to small changes in breeding time (e.g., Gibbs and Breisch 2001; Charmantier et al. 2008), body size (e.g., Teplitsky et al. 2008), or body proportions (e.g., James 1983), rather than large changes in traits closely related to fitness. Several studies of long-lived vertebrates have shown plasticity in recruitment or reproductive rates in response to fluctuating environments but reported relatively stable survival rates (Gaillard et al. 1998; Blomberg et al. 2012, 2013; Morano et al. 2013). Even though our study was too short to provide conclusive results, it is the first reported case we know of where a vertebrate population shows extreme fluctuations in both survival rate and recruitment rate in response to predictable environmental fluctuations.

Life-history plasticity is predicted to evolve in response to predictable environmental fluctuations that are short relative to the organism's typical life span (Botero et al. 2015). In the case of $C$. rosei, rainfall might be a reliable cue for hydroperiod, which determines male breeding success and survival of tadpoles. A clear trade-off between current reproduction and future survival should also lead to increased plasticity as individuals allocate their resources to the fitness component for which the environment is most favorable. Clear costs of reproduction have been found in other ectothermic vertebrates (Bonnet et al. 2002) and might be common in organisms that rely on stored reserves for reproduction (i.e., capital breeders: Bonnet et al. 1998). Male C. rosei do not forage during the breeding season, and their reserves might therefore determine how long they can stay at a breeding pool as well as their chances of survival after the breeding season. More data are needed on the demography of C. rosei to solidify the results we have presented, but the currently available data strongly suggest that the breeding biology of this species has been molded to adaptively respond to the annual variation in rainfall that it experiences. Relatively few detailed demographic data exist on ectothermic vertebrates, but those that do exist point to an intriguing diversity of life histories, such as large fluctuation in survival (Anholt et al. 2003), susceptibility to weather (Altwegg et al. 2005), and annual life cycles (Karsten et al. 2008). Compared to better-studied groups of vertebrates (e.g., Sæther et al. 2000; Coulson et al. 2001), relatively little is known about the demographic mechanisms by which climatic variation affects population dynamics in ectothermic vertebrates. Yet this is critical for understanding how these organisms react to climate change (Urban et al. 2014). 


\section{Conclusions}

The level of environmentally induced life-history plasticity that we report here is far larger than has been previously reported for any vertebrate species (but see Anholt et al. 2003). We suggest that this may in part be due to the taxonomic biases in detailed demographic studies, which have led to a more detailed knowledge of life-history plasticity in birds and mammals, compared to other vertebrates. Our results may thus reflect a broader diversity in life-history strategies among vertebrates than is currently appreciated.

\section{Acknowledgments}

We thank Brad Anholt for commenting on the manuscript and Emily Cressey, Shelley Edwards, Paula Strauss, Tlou Manyelo, Tesray Linveeve, Tessa van der Lingen, and Hanlie Engelbrecht for assisting with the data gathering. We acknowledge the primary financial support of the South African National Biodiversity Institute-National Biodiversity Monitoring Program. Thanks to the University of Cape Town and the South African National Research Foundation (NRF) for additional funding. The NRF accepts no liability for opinions, findings, and conclusions or recommendations expressed in this publication. We thank South African National Parks (SANParks) for the permission to work at the breeding sites as well as their support and helpfulness during this project. In particular, we thank Leighan Mossop, Justin Buchman, and Marisa de Kock from SANParks for their personal involvement, assistance, and helpfulness during the project.

\section{Literature Cited}

Altwegg, R., S. Dummermuth, B. R. Anholt, and T. Flatt. 2005. Winter weather affects asp viper Vipera aspis population dynamics through susceptible juveniles. Oikos 110:55-66.

Anholt, B. R., H. Hotz, G. D. Guex, and R. D. Semlitsch. 2003. Overwinter survival of Rana lessonae and its hemiclonal associate Rana esculenta. Ecology 84:391-397.

Bårdsen, B.-J., P. Fauchald, T. Tveraa, K. Langeland, N. G. Yoccoz, and R. A. Ims. 2008. Experimental evidence of a risk-sensitive reproductive allocation in a long-lived mammal. Ecology 89:829837.

Bårdsen, B.-J., J.-A. Henden, P. Fauchald, T. Tveraa, and A. Stien. 2011. Plastic reproductive allocation as a buffer against environmental stochasticity - linking life history and population dynamics to climate. Oikos 120:245-257.

Benton, T. G., and A. Grant. 1999. Optimal reproductive effort in stochastic, density-dependent environments. Evolution 53:677-688.

Blomberg, E. J., J. S. Sedinger, M. T. Atamian, and D. V. Nonne. 2012. Characteristics of climate and landscape disturbance influence the dynamics of greater sage-grouse populations. Ecosphere 3(6):55. doi:10.1890/ES11-00304.1.
Blomberg, E. J., J. S. Sedinger, D. V. Nonne, and M. T. Atamian. 2013. Seasonal reproductive costs contribute to reduced survival of female greater sage-grouse. Journal of Avian Biology 44:149158.

Bonnet, X., D. Bradshaw, and R. Shine. 1998. Capital versus income breeding: an ectothermic perspective. Oikos 83:333-342.

Bonnet, X., O. Lourdais, R. Shine, and G. Naulleau. 2002. Reproduction in a typical capital breeder: costs, currencies, and complications in the aspic viper. Ecology 83:2124-2135.

Botero, C. A., F. J. Weissing, J. Wright, and D. R. Rubenstein. 2015. Evolutionary tipping points in the capacity to adapt to environmental change. Proceedings of the National Academy of Sciences of the USA 112:184-189.

Burnham, K. P., and D. R. Anderson. 2002. Model selection and multimodel inference: a practical information-theoretic approach. 2nd ed. Springer, New York.

Channing, A., G. J. Measey, A. L. De Villiers, A. A. Turner, and K. A. Tolley. 2017. Taxonomy of the Capensibufo rosei group (Anura: Bufonidae) from South Africa. Zootaxa 4232:282-292.

Charmantier, A., R. H. McCleery, L. R. Cole, C. Perrins, L. E. B. Kruuk, and B. Sheldon. 2008. Adaptive phenotypic plasticity in response to climate change in a wild bird population. Science 320 : 800-803.

Choquet, R., J.-D. Lebreton, O. Gimenez, A. M. Reboulet, and R. Pradel. 2009. U-CARE: utilities for performing goodness of fit tests and manipulating capture-recapture data. Ecography 32:10711074.

Coulson, T., E. A. Catchpole, S. D. Albon, B. J. T. Morgan, J. M. Pemberton, T. H. Clutton-Brock, M. J. Crawley, and B. T. Grenfell. 2001. Age, sex, density, winter weather, and population crashes in Soay sheep. Science 292:1528-1531.

Cressey, E. R., G. J. Measey, and K. A. Tolley. 2015. Fading out of view: the enigmatic decline of Rose's mountain toad Capensibufo rosei. Orvx 48:521-528.

Drent, R., and S. Daan. 1980. The prudent parent: energetic adjustments in avian breeding. Ardea 68:225-252.

Edwards, S., K. A. Tolley, and G. J. Measey. 2017. Habitat characteristics influence the breeding of Rose's dwarf mountain toadlet Capensibufo rosei (Anura: Bufonidae). Herpetological Journal 27: 287-298.

Ehrlén, J. 2003. Fitness components versus total demographic effects: evaluating herbivore impacts on a perennial herb. American Naturalist 162:796-810.

Gaillard, J.-M., M. Festa-Bianchet, and N. G. Yoccoz. 1998. Population dynamics of large herbivores: variable recruitment with constant adult survival. Trends in Ecology and Evolution 13:58-63.

Gaillard, J.-M., and N. G. Yoccoz. 2003. Temporal variation in survival of mammals: a case of environmental canalization? Ecology 84:3294-3306.

Gibbs, J. P., and A. R. Breisch. 2001. Climate warming and calling phenology of frogs near Ithaca, New York. Conservation Biology 15:1175-1178.

Grandison, A. G. C. 1980. A new genus of toad (Anura: Bufonidae) from the Republic of South Africa with remarks on its relationships. Bulletin of the British Museum of Natural History 39:293297.

Hillman, S. S., R. C. Drewes, M. S. Hendrick, and T. V. Hancock. 2014. Physiological vagility: correlations with dispersal and population genetic structure of amphibians. Physiological and Biochemical Zoology 87:105-112. 
James, F. C. 1983. Environmental component of morphological differentiation in birds. Science 221:184-186.

Jones, O. R., A. Scheuerlein, R. Salguero-Gómez, C. G. Camarda, R. Schaible, B. B. Casper, J. P. Dahlgren, et al. 2014. Diversity of ageing across the tree of life. Nature 505:169-173.

Karsten, K. B., L. N. Andriamandimbiarisoa, S. F. Fox, and C. J. Raxworthy. 2008. Discovery of a unique tetrapod life history: and annual chameleon living mostly as an egg. Proceedings of the National Academy of Sciences of the USA 105:8980-8984.

Lebreton, J.-D., K. P. Burnham, J. Clobert, and D. R. Anderson. 1992. Modeling survival and testing biological hypotheses using marked animals: a unified approach with case studies. Ecological Monographs 62:67-118.

Lemckert, F. L., and R. Shine. 1993. Costs of reproduction in a population of the frog Crinia signifera (Anura: Myobatrachidae) from southeastern Australia. Journal of Herpetology 27:420-425.

Merilä, J., and A. P. Hendry. 2014. Climate change, adaptation, and phenotypic plasticity: the problem and the evidence. Evolutionary Applications 7:1-14.

Morano, S., K. M. Stewart, J. S. Sedinger, C. A. Nicolai, and M. Vavra. 2013. Life-history strategies of North American elk: trade-offs associated with reproduction and survival. $\underline{\text { Journal of Mammalogy }}$ 94:162-172.

Morton, M. 1981. Seasonal changes in total body lipid and liver weight in the Yosemite toad. Copeia 1981:234-238.

Pfister, C. A. 1998. Patterns of variance in stage-structured populations: evolutionary predictions and ecological implications. Proceedings of the National Academv of Sciences of the USA 95:213218.

Pradel, R. 1996. Utilization of capture-mark-recapture for the study of recruitment and population growth rate. Biometrics 52:703709.

Ranta, E., D. Tesar, and A. Kaitala. 2002. Environmental variability and semelparity vs. iteroparity as life histories. Journal of Theoretical Biology 217:391-396.

Rebelo, A. G., C. Boucher, N. Helme, L. Mucina, and M. C. Rutherford. 2006. Fynbos biome. Pages 53-219 in L. Mucina and M. C. Rutherford, eds. The vegetation of South Africa, Lesotho and Swaziland. Strelitzia 19. South African National Biodiversity Institute, Pretoria.
Sæther, B.-E. 1988. Pattern of covariation between life-history traits of European birds. Nature 331:616-617.

Sæther, B.-E., T. H. Ringsby, and E. Roskaft. 1996. Life history variation, population processes and priorities in species conservation: towards a reunion of research paradigms. Oikos 77:217-226.

Sæther, B.-E., J. Tufto, S. Engen, K. Jerstad, O. W. Røstad, and J. E. Skåtan. 2000. Population dynamical consequences of climate change for a small temperate songbird. Science 287:854-856.

Skalski, J. R., A. Hoffmann, and S. G. Smith. 1993. Testing the significance of individual and cohort-level covariates in animal survival studies. Pages 9-28 in J.-D. Lebreton and P. M. North, eds. Marked individuals in the study of bird populations. Birkhäuser, Basel, Switzerland.

Stearns, S. C. 1980. A new view of life-history evolution. Oikos 35:266-281.

- 1983. The influence of size and phylogeny on patterns of covariation among life-history traits in mammals. Oikos 41:173-187. . 1992. The evolution of life histories. Oxford University Press, New York.

Teplitsky, C., J. A. Mills, J. S. Alho, J. W. Yarrall, and J. Merilä, J. 2008. Bergmann's rule and climate change revisited: disentangling environmental and genetic responses in a wild bird population. Proceedings of the National Academy of Sciences of the USA 105: 13492-13496.

Ummenhofer, C. C., and G. A. Meehl. 2017. Extreme weather and climate events with ecological relevance-a review. Philosophical Transactions of the Roval Society B 372:20160135. doi:10.1098 /rstb.2016.0135.

Urban, M. C., J. L. Richardson, and N. A. Freidenfelds. 2014. Plasticity and genetic adaptation mediate amphibian and reptile responses to climate change. Evolutionarv Applications 7:88-103.

White, G. C., and K. P. Burnham. 1999. Program MARK: survival estimation from populations of marked animals. Bird Study 46: S120-S139.

Withers, P. C., S. S. Hillman, and R. C. Drewes. 1984. Evaporative water loss and skin lipids of anuran amphibians. Lournal of Experimental Zoology 232:11-17.

Natural History Editor: Mark A. McPeek 